Document downloaded from:

http://hdl.handle.net/10251/146499

This paper must be cited as:

Castells-Gil, J.; Padial, NM.; Almora-Barrios, N.; Albero-Sancho, J.; Ruiz-Salvador, AR.; Gonzalez-Platas, J.; García Gómez, H.... (2018). Chemical Engineering of Photoactivity in Heterometallic Titanium-Organic Frameworks by Metal Doping. Angewandte Chemie International Edition. 57(28):8453-8457. https://doi.org/10.1002/anie.201802089

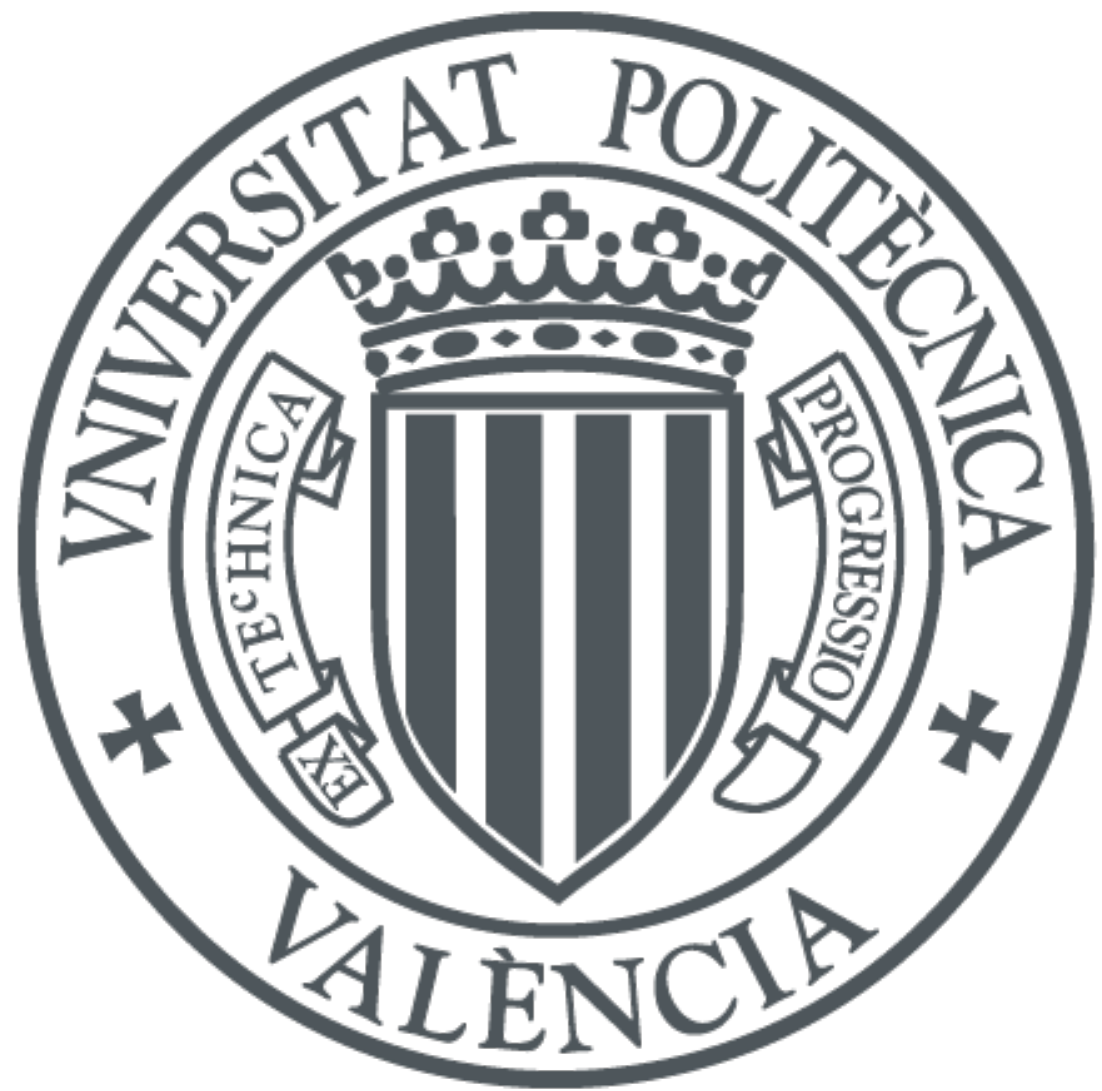

The final publication is available at

https://doi.org/10.1002/anie.201802089

Copyright John Wiley \& Sons

Additional Information 


\title{
Chemical Engineering of Photoactivity in Heterometallic Titanium- Organic Frameworks by Metal Doping
}

\author{
Javier Castells-Gil,${ }^{\dagger}$ Natalia M. Padial, ${ }^{\dagger}$ Neyvis Almora-Barrios, ${ }^{\dagger}$ Josep Albero, ${ }^{\S}$ A. Rabdel Ruiz-Salva- \\ dor, ${ }^{\ddagger}$ Javier González-Platas, $"$ Hermenegildo García, ${ }^{\S}$ Carlos Martí-Gastaldo*,† \\ ${ }^{\dagger}$ Universidad de Valencia (ICMol), Catedrático José Beltrán-2, 46980, Paterna (Spain) \\ *Department of Physical, Chemical and Natural Systems, Universidad Pablo de Olavide, Ctra. de Utrera, Km. 1, 41013 Se- \\ villa (Spain) \\ § Instituto Universitario de Tecnología Química CSIC-UPV, Universitat Politècnica de València, Av. De los Naranjos s/n, \\ 46022, Valencia (Spain).
}

" Departamento de Física, Universidad de La Laguna, E-38200 San Cristóbal de La Laguna, Santa Cruz de Tenerife (Spain)

Here we engineer the optical response of chemically robust, photoactive, heterometallic Ti(IV)-MOFs by metal doping. MUV-10 can be prepared as single crystals by direct synthesis at multi-gram scale. Compared to other methodologies based on the post-synthetic modification of MOFs, our approach is well fitted for controlling the positioning of dopants at an atomic level to gain more precise control over the band gap and electronic properties of the porous solid.

Metal-Organic Frameworks (MOFs) are crystalline, molecular solids built from the linking of organic and inorganic components with coordinative bonds.di MOFs feature incomparable chemical diversity and sizeable three-dimensional porosity ideal for applications like gas storage, separation or catalysis. ${ }^{1,2}$ However, they often suffer from poor chemical stability -particularly in humid conditions- limiting their performance and preventing large-scale application. ${ }^{3}$ Chemically robust MOFs can be produced by using basic nitrogenated linkers ${ }^{4,5}$ or highly charged metals like $\mathrm{Zr}$ or $\mathrm{Hf}(\mathrm{IV}),{ }^{6-8}$ for endowing the framework with stronger metal-linker bonds less prone to hydrolysis.

Compared to these metals, titanium is naturally more abundant and features advantageous properties like low toxicity, redox versatility and potential photocatalytic activity. However, the synthesis of carboxylate-bridged Ti(IV), crystalline, porous materials remains still a synthetic challenge. ${ }^{9}$ This is arguably due to the high reactivity of Ti precursors, which are prone to hydrolysis in the solvothermal conditions conventional to MOF synthesis to form amorphous $\mathrm{TiO}_{2}$. As result, only a few Ti(IV)MOFs like MIL-125, ${ }^{10}$ NTU-9 $9{ }^{11}$ and COK-69, ${ }^{12}$-synthesised from simple Ti precursors- or PCN-22 ${ }^{13}$ and PCN- $415^{14}$-by using preformed clusters-, have been prepared by direct reaction with polycarboxylate linkers. Also relevant is the use of imine condensation reactions, typical of COF chemistry, for the cross-linking of Ti oxo clusters in MOF-901. ${ }^{15}$

Applications of Ti-MOFs in photocatalysis for redox reactions, solar fuel production or light-induced organic transformations are continuously expanding due to the unique properties that can arise from the combination of high surface area, crystallinity good photo-stability and photo-activity. ${ }^{16,17}$ Moreover, compared to traditional inorganic semiconductors like $\mathrm{TiO}_{2}$, photocatalytic activity can be finely tuned by direct modification of the organic linker to enhance light absorption in the visible region. This can be attained by functionalization of the linker with substituents to shift light absorption as exemplified by NH2-MIL-125. ${ }^{18-20}$ Still, other routes often used with oxide semiconductors remain underexplored. Here we present a new family of chemically robust, photoactive titanium-organic frameworks coined MUV-10 (MUV = Materials of Universidad de Valencia), that can be prepared as single-crystals at multigram scale. Compared to other Ti-MOFs, their structure is based on heterometallic SBUs. We use this feature to investigate the impact of incorporating open-shell metals over the electronic structure of the framework for tunable photoactivity.

MUV-10(Ca) was first synthesized by solvothermal reaction of titanium (IV) isopropoxide, calcium chloride and trimesic acid ( $\mathrm{H}_{3}$ btc; benzene-1,3,5-tricarboxylic acid) in $N, N$-dimethylformamide (DMF), by using acetic acid as modulator (SI2). Heating at $120^{\circ} \mathrm{C}$ for 48 hours results in quantitative formation of colourless, octahedral crystals of micrometric size of formula $\left[\mathrm{Ti}^{\mathrm{IV}}{ }_{3} \mathrm{Ca}_{3}{ }_{3}\left(\mu_{3}-\mathrm{O}\right)_{2}(\mathrm{btc})_{4}\left(\mathrm{H}_{2} \mathrm{O}\right)_{6}\right] \cdot$ solvent (Figure 1). According to our single-crystal X-Ray diffraction study, MUV-10(Ca) crystallises in the cubic space group $\mathrm{P} m-3$ (SI3). It is a threedimensional, porous solid built from the interlinking of fully deprotonated trimesate anions and tetranuclear $\mathrm{Ti}^{1{ }^{1}}{ }_{2} \mathrm{Ca}_{2}{ }_{2}\left(\mu_{3}-\right.$ $\mathrm{O})_{2}\left(\mathrm{H}_{2} \mathrm{O}\right)_{4}\left(\mathrm{CO}_{2}\right)_{8}$ clusters (Figure 2a). This tetranuclear SBU is composed of six-coordinated octahedral Ti(IV) and six-coordinated $\mathrm{Ca}$ (II) centres with a trigonal prismatic geometry, that are interconnected by eight carboxylates acting as $\mu_{2}$-bridges, two

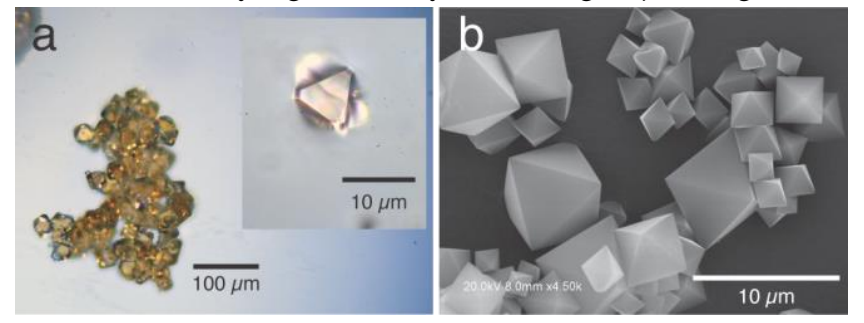

Figure 1. Size and morphology of as-made MUV-10(Ca) crystals examined with a) optical microscope and b) SEM. 

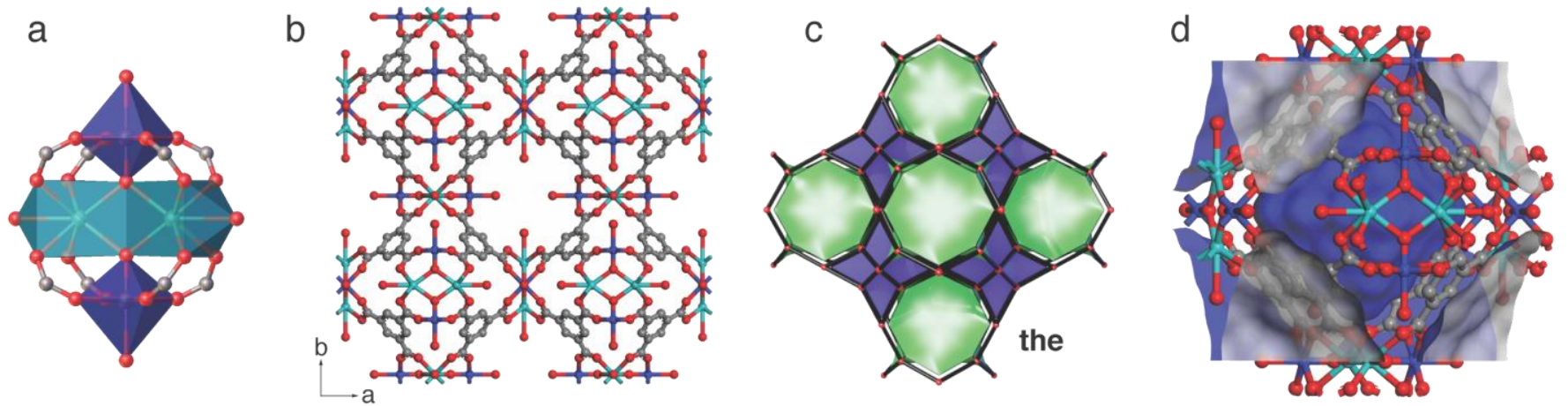

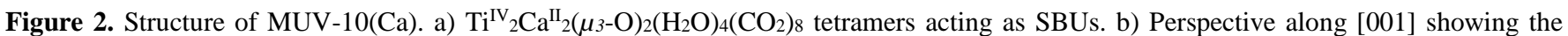
overall structure of the 3,8-connected framework. c) Natural tiling of polyhedral cages in the the underlying net of MUV-10. d) Internal structure of the sodalite-type octahedral cages.

$\mu_{3}$-oxo anions and water molecules to complete the positions left at their coordination sphere. There are examples of neutral clusters with this structure in the literature (Table S2) but, as far as we know, this SBU remained still missing in MOF chemistry. Overall, each tetranuclear cluster is connected to eight neighbouring SBUs by eight btc linkers, four above and four below the plane of the tetramer, to conform a neutral framework with cubic symmetry (Figure $\mathbf{2 b}$ ). The SBU was found to be in a two-fold rotational disorder without affecting the overall structure (Figure S2a-b). For a clearer structural description, Figure 2c shows the underlying net of MUV-10(Ca) as calculated with ToposPro ${ }^{21}$ and Systre ${ }^{22}$. Each btc unit acts as a 3-c node and links 8-c SBUs into a $(3,8)$-connected the net. This topology is quite elusive and has been only reported for frameworks based on the combination of $\mathrm{M}^{\mathrm{II}}{ }_{4} \mathrm{Cl}(\mathrm{M}=\mathrm{Mn}, \mathrm{Cu})$ and $\mathrm{Zr}_{6} \mathrm{O}_{4}(\mathrm{OH})_{4}\left(\mathrm{RCO}_{2}\right)_{12}$ SBUs with linkers featuring $D_{3 h}$ symmetry either for tetrazolate ${ }^{23}$ or carboxylate connectors. ${ }^{24-26}$ This arrangement results in an open framework with 3D intersected channels and octahedral cages formed by six SBUs and eight btc molecules, that account for a solvent-accessible volume close to $50 \%$ of the total (Table S5). The resulting sodalite-type cages can accommodate spheres with an internal diameter of 1.2 $\mathrm{nm}$ and display square windows with free apertures slightly above $0.5 \mathrm{~nm}$ (Figure S2c).

As already pointed out, the synthetic difficulties inherent to the production of Ti-MOFs is one of the key limitations for further development in this area. This pushed us to optimize its synthesis and investigate the effect of the metal precursor over the solids formed. MUV-10(Ca) can be produced at a gramscale with yields close to $80 \%$ by simple upscaling of reagents. We selected a list of different precursors commonly used in the synthesis of Ti-MOFs like Ti(IV) isopropoxide, ${ }^{10,11} \mathrm{Cp}_{2} \mathrm{TiCl}_{2}{ }^{12}$ or a preformed $\mathrm{Ti}_{6} \mathrm{O}_{6}\left(\mathrm{O}^{\mathrm{i}} \mathrm{Pr}\right)_{6}\left(\mathrm{O}_{2} \mathrm{C}\right)_{6} \mathrm{SBU}{ }^{14,27}$ Though the precursor is considered crucial for the formation of crystalline materials, our experiments confirm that MUV-10(Ca) can be prepared as single-crystals in all cases. Still, it seems to affect their size moderately as it increases from $\mathrm{XXX}$ to $\mathrm{XXX} \mu \mathrm{m}$ according to the sequence $\mathrm{Cp}_{2} \mathrm{TiCl}_{2}>\mathrm{Ti}_{6} \mathrm{O}_{6}\left(\mathrm{O}^{\mathrm{i}} \mathrm{Pr}\right)_{6}\left(\mathrm{O}_{2} \mathrm{C}\right)_{6}>\mathrm{Ti}\left(\mathrm{O}^{\mathrm{i}} \mathrm{Pr}\right)_{4}$ (Figure S1).

Phase purity was confirmed by LeBail refinement of the powder X-ray diffraction (PXRD, Figure S7a), thermogravimetric analysis (TGA) and scanning electron microscopy (SEM). MUV-10(Ca) remains stable up to $450{ }^{\circ} \mathrm{C}$ (Figure S8). This thermal stability is very similar to other Ti-MOFs like MIL$125 .^{10}$ SEM was used to rule out metal clustering and confirm the homogeneous distribution of $\mathrm{Ca}$ and $\mathrm{Ti}$ throughout the sample (Figure S5). Porosity was studied by $\mathrm{N}_{2}$ adsorption-desorption isotherms at $77 \mathrm{~K}$ after activation of the solid under dynamic vacuum $\left(10^{-3} \mathrm{mbar}\right)$ at $150{ }^{\circ} \mathrm{C}$ overnight. MUV-10(Ca) displays type-I reversible $\mathrm{N}_{2}$ adsorption with no hysteresis, characteristic of microporous materials. The multi-point BET surface area was found to be $1041 \mathrm{~m}^{2} \cdot \mathrm{g}^{-1}$ with a total pore volume of $0.40 \mathrm{~cm}^{3} \cdot \mathrm{g}^{-1}$ (Table S4, Figure S9). Analysis of the pore size distribution (PSD) by using non-linear density functional theory (NLDFT) methods reveals a homogeneous pore diameter of $10.3 \AA$, that agrees well the value of $12.0 \AA$ calculated from the structure. MUV-10(Ca) also adsorbs a significant amount of $\mathrm{CO}_{2}, 4.56 \mathrm{mmol} . \mathrm{g}^{-1}(20.1 \%)$ at $293 \mathrm{~K}$ and 1 bar, with

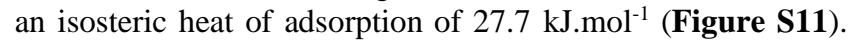
Although the introduction of divalent metals in the SBU might act as weak points towards hydrolysis, compromising the stability of the material, MUV-10(Ca) maintains its structural integrity between $\mathrm{pH} 2$ and 12. According to the PXRD LeBail refinements (Figures S14-16) and $\mathrm{N}_{2}$ adsorption measurements (Figure S20, Table S6), soaking of the solid in concentrated solutions of $\mathrm{HCl}$ and $\mathrm{NaOH}(\mathrm{aq})$ during 24 hours does not affect its crystallinity or surface area. As pointed out in the introduction, there is a limited number of MOFs showing hydrolytical stability in these conditions. MUV-10 shows excellent chemical stability, comparable to other benchmark materials, ${ }^{3}$ likely due to the presence of strong Ti-O coordination bonds in the structure.

Asides chemical stability, Ti(IV) nodes are also expected to render photoactive MOFs. To investigate this possibility we calculated the electronic structure of MUV-10(Ca) by using density functional theory (DFT; see SI6 for computational methodology). As shown in Figure 3a, the electronic density of states diagram (DOS) suggests that this material is a semiconductor with a band gap of $3.1 \mathrm{eV}$, in good agreement with the optical value extracted from diffuse reflectance spectroscopy (DRS) measurements according to the Kubelka-Munk function (Figure S12). Similar to other Ti-MOFs, ${ }^{12,14,19}$ the conduction band $(\mathrm{CB})$ is dominated by Ti $3 \mathrm{~d}$ orbitals, whereas the valence band (VB) is composed mainly by 2 p orbitals from the aromatic btc units. The calculated band gap is compatible with UV light photoactivity. To probe this point, we irradiated MUV-10(Ca) in deoxygenated THF with UV-B light $(\lambda=280-400 \mathrm{~nm})$. This produced a change in color from white to dark brown in less than 2 hours. This change remains stable with time and reverts back instantaneously by exposure of the solid to open air. As shown in Figure S13a, the Electron Paramagnetic Resonance (EPR) spectra of MUV-10(Ca) before and after irradiation 
a

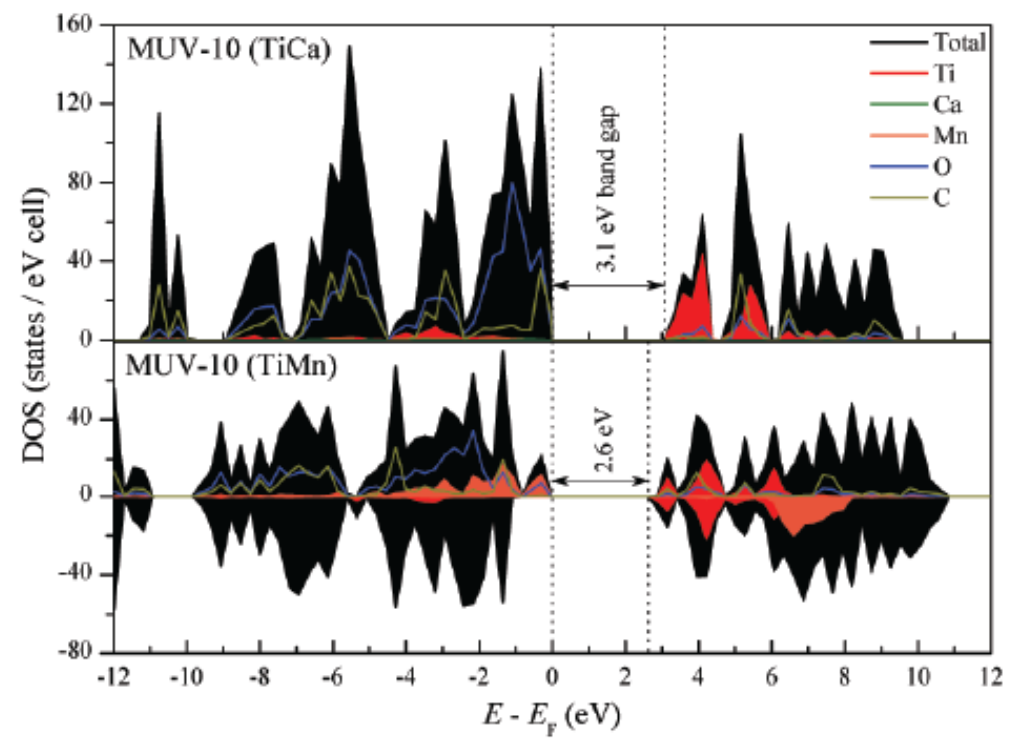

Figure 3. Electronic structure of MUV-10 family. a) Total electronic density of states (DOS, black curve) for MUV-10(Ca) (top) and MUV-10(Mn) (bottom) calculated by using the screened hybrid functional HSE06. Contribution of Ti, Ca, Mn, C and $\mathrm{O}$ atoms to the DOS are shown in colour. The valence band and conduction band edges are indicated with a dashed line. b) Electron density in the VB of both solids.

shows the appearance of two signals only for the last. A broad signal at $0.35 \mathrm{~T}$ with $\mathrm{g}$ fitted parameters $\mathrm{g}_{\|}=1.975$ and $\mathrm{g}_{\perp}=$ 1.946, characteristic of $\mathrm{Ti}(\mathrm{III})$ species, and a sharper one at lower fields with a $\mathrm{g}=2.00$ that can be attributed to the formation of btc radicals. This is indicative of the photoreduction of the linker to generate an excited state that transfers the charge to the Ti(IV) metal nodes upon ligand-to-metal charge transfer (LMCT).

In general, MOFs featuring LMCTs like MIL-125 are preferable for photocatalytic purposes due to more efficient charge separation if compared to other systems in which photoexcitation only affects isolated linkers or metals. ${ }^{28}$ Also, MUV$10(\mathrm{Ca})$ displays excellent chemical stability key to circumvent the drastic conditions often used in photocatalytic experiments. However, we identified its inability to operate with visible light as an important limitation in this context. As exemplified for MIL-125- $\mathrm{NH}_{2}$ and UiO- $\mathrm{NH}_{2}$ families, more efficient light harvesting can be accomplished by ligand engineering. ${ }^{19,20}$ The structure of MUV-10 seems instead, more adequate to investigate the effect of incorporating open-shell metals over its photoactivity. In order to identify the best candidate, we calculated the enthalpies and free energies for exchanging $\mathrm{Ca}$ (II) with several transition metal cations. Our calculations suggest that the incorporation of $\mathrm{Mn}$ (II) to the heterometallic clusters in MUV10 is the most favorable thermodynamically (S6, Table S8). This prediction is consistent with previous theoretical studies, suggesting that trigonal prism coordination is preferred by metals with high-spin $\mathrm{d}^{5}$ configurations like Mn(II). ${ }^{29}$ Accordingly, we attempted to prepare MUV-10(Mn) by direct synthesis by following the same procedure used for MUV-10(Ca) by using manganese chloride. This derivative is isostructural to the calcium analogue as confirmed by LeBail refinement of the PXRD (Figure S7b). Equimolar ratio of $\mathrm{Ti}$ and $\mathrm{Mn}$ was confirmed with SEM (Figure S6). MUV-10(Mn) also displays equivalent thermal stability (Figure $\mathbf{S 8}$ ), $\mathrm{N}_{2}$ and $\mathrm{CO}_{2}$ sorption capabilities (Table S4, Figures S10 and S11) than MUV-10(Ca), with minimum changes associated to a slight contraction of the unit cell b

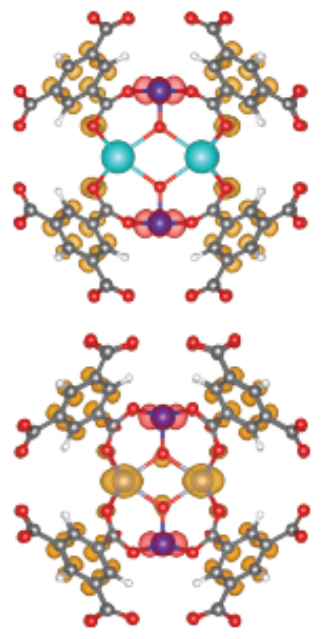

due to the smaller ionic radius of $\mathrm{Mn}(\mathrm{II})(0.83$ vs. $1.06 \AA)$. We also examined the chemical stability of MUV-10(Mn) in extreme acid and basic conditions. According to the PXRD (Figures S17-20) and $\mathrm{N}_{2}$ sorption analysis (Figure S21, Table S7), the structure and porosity of the solid remains intact after water treatment between a broader range of $\mathrm{pH}$, from 1 to 12 . We attribute this increase in stability to the presence of stronger Mn-O coordination bonds. As shown in Figure 3a, the incorporation of $\mathrm{Mn}(\mathrm{II})$ units to the structure of MUV-10 also affects its electronic structure, reducing the band gap to 2.6 $\mathrm{eV}$. This is consistent with the experimental red shift of the absorption peak in the DRS for an optical band gap of 2.56 eV (Figure S12). This change is directly linked to the introduction of d electrons. Closed-shell $\mathrm{Ca}$ (II) centers in MUV$10(\mathrm{Ca})$, only contribute to the DOS deep inside the VB states without modifying the electronic structure around the band gap. In turn, d orbitals from $\mathrm{Mn}$ (II) contribute significantly to the upper VB and the edge of the CB for a narrowing of the band gap (Figure 3b). Photoactivity with visible-light was next analyzed with EPR of MUV-10(Mn) under equivalent conditions but using Vis-X light ( $\lambda=280-400 \mathrm{~nm})$. We observed a rapid change of color into dark blue upon irradiation, suggesting the formation of $\mathrm{Ti}$ (III) species also centered at $0.35 \mathrm{~T}$. Unfortunately, the coupling with the electronic spin of paramagnetic $\mathrm{Mn}$ (II) makes difficult further analysis (Figure S13b).

For a clearer demonstration of the superior activity of MUV$10(\mathrm{Mn})$ with visible light, we next tested the activity of both derivatives as photocatalysts for $\mathrm{H}_{2}$ generation. Irradiation of a suspension of the solids in $\mathrm{H}_{2} \mathrm{O}: \mathrm{CH}_{3} \mathrm{OH}$ with simulated solar light (300 W Xe lamp) confirms that the Mn- containing MUV10 triples the activity of the $\mathrm{Ca}$ one with a faster induction rate for a total of $75 \mu \mathrm{mol} . \mathrm{g}^{-1} \cdot \mathrm{h}^{-1}$ after 24 hours of irradiation (Figure 4). Stability after the experiments was confirmed with PXRD (See SI7 for details). MUV-10(Mn) displays a superior photocatalytic activity than $\mathrm{NH}_{2}$-MIL-125 $(5 \mu \mathrm{mol})$ under equivalent experiment conditions. ${ }^{18}$ Optimization of $\mathrm{H}_{2}$ production by use of co-catalysts and alternative electron donors is ongoing.

MOFs are relatively new materials in the field of photoactivated transformations, but they are receiving increasing attention thanks to their incomparable chemical versatility, useful to optimize performance by chemical design. Here we report a new family of heterometallic titanium-organic frameworks that enlarges the limited number of crystalline, porous materials available. MUV-10 can be prepared as single-crystals at a multi-gram scale and display excellent chemical stability. The heterometallic clusters in their structure conforms and excellent platform to manipulate their electronic structure and photoactivity by metal doping rather than linker functionalization. Compared to other methodologies based on post-synthetic 


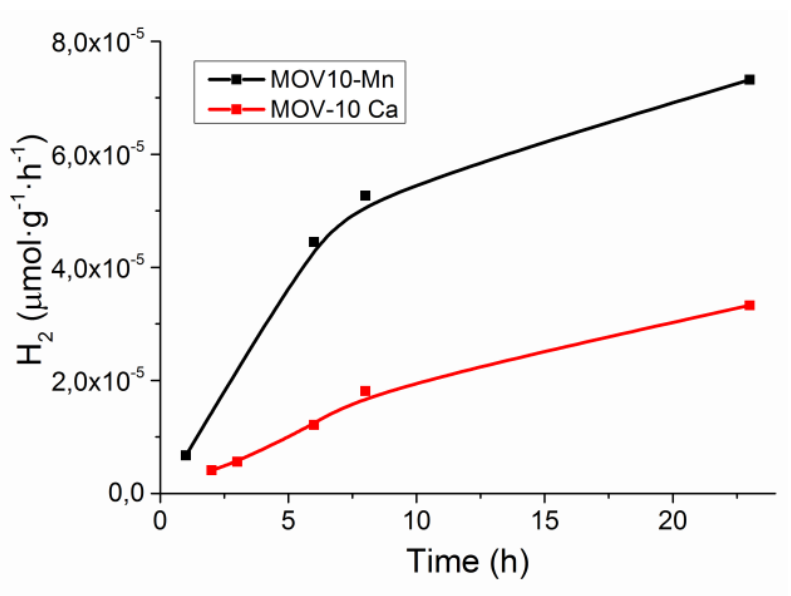

Figure 4. Photocatalytic generation of hydrogen after 24 hours of irradiation. We used $\mathrm{X} \mathrm{mg}$ of $\mathrm{MOF}$ in $\mathrm{XX} \mathrm{mL}$ of $\mathrm{H}_{2} \mathrm{O}: \mathrm{CH}_{3} \mathrm{OH}(\mathrm{X}: \mathrm{X})$ in both measurements.

metal exchange of MOFs by metathesis reaction with Ti(IV) or Ti(III) precursors followed by oxidation, ${ }^{27,30}$ our approach is simpler and better fitted for controlling the positioning of dopants at an atomic level at doping levels as high as $50 \%$. Based on their high-stability and tunable photoactivity, we expect this new family of materials to accelerate the design of advanced TiMOF photocatalysts.

\section{ASSOCIATED CONTENT}

\section{Supporting Information}

The Supporting Information is available free of charge on the ACS Publications website.

Synthetic and experimental details. Physical characterization and supporting tables and figures (PDF)

\section{AUTHOR INFORMATION}

\section{Corresponding Author}

*carlos.marti@uv.es

\section{ACKNOWLEDGMENT}

This work was supported by the EU (ERC Stg Chem-fs-MOF 714122) and Spanish MINECO (MDM-2015-0538 \& CTQ201783486-P). C.M.-G. and J.C.-G. thank the Spanish MINECO for a Ramón y Cajal Fellowship and FPI Scholarship (CTQ2014-59209P), respectively. N.M.P. thank the Junta de Andalucía for post-doctoral fellowship (P10-FQM-6050). BSC-RES is acknowledged for the computational resources and F. Lloret for helpful discussions.

\section{REFERENCES}

(1) Furukawa, H.; Cordova, K. E.; O'Keeffe, M.; Yaghi, O. M. Science 2013, 341 (6149), 1230444.

(2) Adil, K.; Belmabkhout, Y.; Pillai, R. S.; Cadiau, A.; Bhatt, P. M.; Assen, A. H.; Maurin, G.; Eddaoudi, M. Chem. Soc. Rev. 2017, 46 (11), 3402.

(3) Howarth, A. J.; Liu, Y.; Li, P.; Li, Z.; Wang, T. C.; Hupp, J. T.; Farha, O. K. Nat. Rev. Mater. 2016, 1 (3), 15018.

(4) Colombo, V.; Galli, S.; Choi, H. J.; Han, G. D.; Maspero, A.; Palmisano, G.; Masciocchi, N.; Long, J. R. Chem. Sci. 2011, 2 (7), 1311.

(5) Park, K.; Ni, Z.; Côté, A.; Choi, J.; Huang, R.; UribeRomo, F.; Chae, H.; O'Keeffe, M.; Yaghi, O. M. Proc. Natl. Acad. Sci. USA 2006, 103 (27), 10186.
Cavka, J.; Jakobsen, S.; Olsbye, U.; Guillou, N.; Lamberti, C.; Bordiga, S.; Lillerud, K. J. Am. Chem. Soc. 2008, 130 (42), 13850.

Devic, T.; Serre, C. Chem. Soc. Rev. 2014, 43 (16), 6097.

Bai, Y.; Dou, Y.; Xie, L.-H.; Rutledge, W.; Li, J.-R.; Zhou, H.-C. Chem. Soc. Rev. 2016, 45 (8), 2327.

Assi, H.; Mouchaham, G.; Steunou, N.; Devic, T.; Serre, C. Chem. Soc. Rev. 2017, 46 (11), 3431.

Dan-Hardi, M.; Serre, C.; Frot, T.; Rozes, L.; Maurin, G.; Sanchez, C.; Ferey, G. J. Am. Chem. Soc. 2009, 131 (31), 10857.

Gao, J.; Miao, J.; Li, P.-Z.; Teng, W. Y.; Yang, L.; Zhao, Y.; Liu, B.; Zhang, Q. Chem. Commun. 2014, 50 (29), 3786.

Bueken, B.; Vermoortele, F.; Vanpoucke, D. E. P.; Reinsch, H.; Tsou, C.-C.; Valvekens, P.; De Baerdemaeker, T.; Ameloot, R.; Kirschhock, C. E. A.; Van Speybroeck, V.; Mayer, J. M.; De Vos, D. Angew. Chem. Int. Ed. Engl. 2015, 54 (47), 13912.

Yuan, S.; Liu, T.-F.; Feng, D.; Tian, J.; Wang, K.; qin, J.; Zhang, Q.; Chen, Y.-P.; Bosch, M.; Zou, L.; Teat, S. J.; Dalgarno, S. J.; Zhou, H.-C. Chem. Sci. 2015, 6 (7), 3926. Yuan, S.; Qin, J.-S.; Xu, H.-Q.; Su, J.; Rossi, D.; Chen, Y.; Zhang, L.; Lollar, C.; Wang, Q.; Jiang, H.-L.; Son, D. H.; Xu, H.; Huang, Z.; Zou, X.; Zhou, H.-C. ACS Cent. Sci. 2017, 4 (1), 105

Nguyen, H. L.; Gándara, F.; Furukawa, H.; Doan, T. L. H.; Cordova, K. E.; Yaghi, O. M. J. Am. Chem. Soc. 2016, 138 (13), 4330

Dhakshinamoorthy, A.; Asiri, A. M.; García, H. Angew. Chem. Int. Ed. 2016, 55 (18), 5414.

Deng, X.; Li, Z.; García, H. Chem-Eur J. 2017, 23 (47), 11189.

Horiuchi, Y.; Toyao, T.; Saito, M.; Mochizuki, K.; Iwata, M.; Higashimura, H.; Anpo, M.; Matsuoka, M. J. Phys. Chem. C 2012, 116 (39), 20848.

Hendon, C. H.; Tiana, D.; Fontecave, M.; Sanchez, C.; D'arras, L.; Sassoye, C.; Rozes, L.; Mellot-Draznieks, C.; Walsh, A. J. Am. Chem. Soc. 2013, 135 (30), 10942. Chambers, M. B.; Wang, X.; Ellezam, L.; Ersen, O.; Fontecave, M.; Sanchez, C.; Rozes, L.; Mellot-Draznieks, C. J. Am. Chem. Soc. 2017, 139 (24), 8222.

Blatov, V. A.; Shevchenko, A. P.; Proserpio, D. M. Cryst. Growth Des. 2014, 14 (7), 3576.

Delgado-Friedrichs, O.; O'Keeffe, M. Acta Crystallogr. Sect. A 2003, 59 (4), 351.

Dincă, M.; Han, W. S.; Liu, Y.; Dailly, A.; Brown, C. M.; Long, J. R. Angew. Chem. Int. Ed. 2007, 46 (9), 1419.

Liu, T.-F.; Vermeulen, N. A.; Howarth, A. J.; Li, P.; Sarjeant, A. A.; Hupp, J. T.; Farha, O. K. Eur. J. Inorg. Chem. 2016, 2016 (27), 4349.

Wang, B.; Lv, X.-L.; Feng, D.; Xie, L.-H.; Zhang, J.; Li, M.; Xie, Y.; Li, J.-R.; Zhou, H.-C. J. Am. Chem. Soc. 2016, 138 (19), 6204.

Tan, Y.-X.; He, Y.-P.; Zhang, J. Chem. Commun. 2011, 47 (38), 10647.

Zou, L.; Feng, D.; Liu, T.-F.; Chen, Y.-P.; Yuan, S.; Wang, K.; Wang, X.; Fordham, S.; Zhou, H.-C. Chem. Sci. 2016, 7 (2), 1063.

Santaclara, J. G.; Kapteijn, F.; Gascon, J.; van der Veen, M. A. CrystEngComm 2017, 19 (29), 4118.

Cremades, E.; Echeverría, J.; Alvarez, S. Chem-Eur J. 2010, 16 (34), 10380.

Brozek, C. K.; Dincă, M. J. Am. Chem. Soc. 2013, 135 (34), 12886. 
SYNOPSIS TOC (Word Style "SN_Synopsis_TOC"). If you are submitting your paper to a journal that requires a synopsis graphic and/or synopsis paragraph, see the Instructions for Authors on the journal's homepage for a description of what needs to be provided and for the size requirements of the artwork.

To format double-column figures, schemes, charts, and tables, use the following instructions:

Place the insertion point where you want to change the number of columns

From the Insert menu, choose Break

Under Sections, choose Continuous

Make sure the insertion point is in the new section. From the Format menu, choose Columns

In the Number of Columns box, type 1

Choose the OK button

Now your page is set up so that figures, schemes, charts, and tables can span two columns. These must appear at the top of the page. Be sure to add another section break after the table and change it back to two columns with a spacing of 0.33 in.

\section{Table 1. Example of a Double-Column Table}

\begin{tabular}{|l|l|l|l|l|l|l|l|}
\hline Column 1 & Column 2 & Column 3 & Column 4 & Column 5 & Column 6 & Column 7 & Column 8 \\
\hline & & & & & & & \\
\hline
\end{tabular}

Authors are required to submit a graphic entry for the Table of Contents (TOC) that, in conjunction with the manuscript title, should give the reader a representative idea of one of the following: A key structure, reaction, equation, concept, or theorem, etc., that is discussed in the manuscript. Consult the journal's Instructions for Authors for TOC graphic specifications.

Insert Table of Contents artwork here

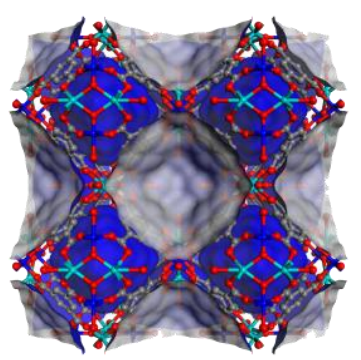

